\title{
Low bone mineral density is associated with hypogonadism and cranial irradiation in male childhood cancer survivors
}

\author{
S. Isaksson ${ }^{1,2}$ (D) K. Bogefors ${ }^{1,2} \cdot$ K. Åkesson ${ }^{3,4} \cdot$ I. Øra ${ }^{5} \cdot$ L. Egund ${ }^{3,4} \cdot$ J. Bobjer ${ }^{1,6}$ - I. Leijonhufvud ${ }^{1,7}$. \\ A. Giwercman ${ }^{1,7}$
}

Received: 27 February 2019 / Accepted: 6 January 2020 / Published online: 1 February 2020

(C) The Author(s) 2020

\begin{abstract}
Summary We investigated if bone mineral density was related to testosterone deficiency and/or previous cancer treatment in men who were childhood cancer survivors. Men with untreated testosterone deficiency or previous treatment with cranial irradiation were at increased risk of impaired bone health. Prevention of osteoporosis should be considered in their follow-up.

Introduction Childhood cancer survivors (CCS) are at increased risk of hypogonadism. Reduced bone mineral density (BMD) has been reported in CCS but it is unclear whether this is due to hypogonadism or a direct effect of cancer therapy. This study investigated BMD in CCS, and association with hypogonadism, previous treatment and cancer type.

Methods Investigation of $125 \mathrm{CCS}$ (median age 33.7 at inclusion; 9.6 at diagnosis) and 125 age-matched population controls. Serum testosterone and luteinizing hormone were assayed and BMD at total hip and lumbar spine L1-L4 measured. The mean difference in BMD $\left(\mathrm{g} / \mathrm{cm}^{2} ; 95 \% \mathrm{CI}\right)$ between CCS and controls was analysed. Odds ratios (OR; $95 \% \mathrm{CI}$ ) for low BMD were also calculated.

Results Overall, BMD in the CCS cohort did not significantly differ from controls. However, compared with eugonadal CCS, the CCS with untreated hypogonadism had lower BMD at the hip (mean difference -0.139 ($0.210 ;-0.067) ; p<0.001)$ and spine $(-0.102(-0.174 ;-0.030) ; p=0.006)$. They also had a higher risk of low hip BMD (OR $4.1(1.3 ; 14) ; p=0.018)$. CCS treated with cranial irradiation also had lower BMD (hip - 0.076 (-0.133; $-0.019) ; p=0.009 ;$ spine $-0.071(-0.124 ;-0.018) ; p=0.009)$ compared with controls. The latter associations remained statistically significant after adjustment for hypogonadism.

Conclusions CCS with hypogonadism or previously treated with cranial irradiation are at increased risk of impaired bone health. Prevention of osteoporosis should be considered as an important part in future follow-up of these men.
\end{abstract}

Keywords Chemotherapy $\cdot$ Childhood cancer $\cdot$ Hypogonadism $\cdot$ Late effects of cancer treatment $\cdot$ Radiotherapy

Electronic supplementary material The online version of this article (https://doi.org/10.1007/s00198-020-05285-4) contains supplementary material, which is available to authorized users.

S. Isaksson

sigrid.isaksson@med.lu.se

1 Molecular Reproductive Medicine Unit, Department of Translational Medicine, Lund University, CRC Building 91, Plan 10, Jan Waldenströms Gata 35, SE-205 02 Malmö, Sweden

2 Department of Oncology, Skane University Hospital, Malmö and Lund, Sweden

3 Department of Clinical Sciences Malmö, Clinical and Molecular Osteoporosis Unit, Lund University, Malmö, Sweden
4 Department of Orthopedics, Skane University Hospital, Malmö, Sweden

5 Pediatric Oncology and Hematology, Clinical Sciences, Lund University, Lund, Sweden

6 Department of Urology, Skane University Hospital, Malmö, Sweden

7 Reproductive Medicine Centre, Skane University Hospital, Malmö, Sweden 


\section{Introduction}

Survival rate for childhood cancer has improved considerably during the last decades and is now approximately $80 \%$ in Europe [1]. Potential long-term adverse consequences from cancer treatment have therefore become increasingly important. Depending on organ system, the time elapsed from cancer treatment to clinical symptoms may be extended, and this is in particular true for skeletal effects. Low bone mineral density (BMD) and osteoporosis often develop over many years. Osteoporosis is defined as a skeletal disorder characterized by compromised bone strength, predisposing to an increased fracture risk. There is no method for measuring overall bone strength, but BMD serves as a proxy [2], since a decreased BMD correlates with increased fracture risk [3]. Although fragility fractures are less prevalent in men than in women, men have higher rates of fracture-related mortality [4]. Because of the morbidity and mortality associated with osteoporotic fractures, it is desirable to identify those at risk of osteoporosis so that preventive measures can be taken.

Among adult childhood cancer survivors (CCS), almost $40 \%$ in the large St Jude Lifetime Cohort Study had low BMD in total body or lumbar spine [5]. Hypogonadism has been stated to be a risk factor of low BMD in CCS [6-8]. Available studies reporting on the association between hypogonadism and BMD in CCS are based on a low number of subjects [9-11], mixing both male and female CCS [8, 10-12] or lacking controls $[8,9,11]$, making conclusions regarding possible association between hypogonadism and BMD in adult male CCS difficult.

To address these shortcomings, we investigated 125 male CCS after a mean follow-up of 24.3 years and a corresponding number of age-matched controls from the general population. Our aims were (1) to investigate differences in BMD and the risk of low BMD in male CCS compared with controls and (2) to elucidate possible associations between BMD and biochemical signs of hypogonadism, previous cancer treatment and type of cancer.

\section{Methods}

This study is based on a cohort of male CCS invited 13 years ago (2005-2006) to participate in a study on reproductive function [13]. However, all the data presented in the current study was collected during 2010-2012, when we asked the patients and controls to re-visit our research unit and undergo investigations related to skeletal health under standardized conditions (see below).

\section{Childhood cancer survivors}

The cohort of CCS was derived from 427 consecutive male CCS identified through the Swedish Cancer Registry, diagnosed with childhood cancer between 1970 and 2002 and living in the region of Skane in southern Sweden at the time of diagnosis. Inclusion criteria were any malignant disease or benign tumour in the central nervous system (CNS) before age 18, being alive as of December 2009 and $>3$ years since the last cancer treatment.

Of those identified through the registry, eleven men were deceased, 10 could not be located and one was transferred to a testicular cancer survival cohort on which we have previously reported [14]. Of the remaining 405 men contacted by letter, 146 accepted to participate in the study. Six subsequently dropped out, one patient with optic glioma was excluded due to management with surveillance only, six were excluded due non-malignant disease (carcinoid of the appendix) and eight were excluded due to a second malignancy or relapse within 3 years of inclusion, leaving a final number of 125 reported on in this manuscript. Thirteen CCS had ongoing testosterone replacement therapy (TRT), eight had glucocorticoid replacement therapy due to pituitary failure, 3 had immunosuppressive oral glucocorticoids due to kidney transplant or Crohn's disease and two were treated with calcium and vita$\min \mathrm{D}$ (Fig. 1).

In order to evaluate possible selection bias based on reproductive function, data on number of biological children for participants and non-participants were extracted from the Swedish Multi-Generation Register. The distribution of CCS having $0,1,2$ or $\geq 3$ children was $52 \%, 14 \%, 29 \%$ and $5.3 \%$ among participants and $65 \%, 14 \%, 17 \%$ and $5.1 \%$ among non-participants.

CCS were categorized into subgroups according to gonadal status, diagnostic subgroups and therapeutic subgroups (see Online Resource for details). Background characteristics of CCS and controls are presented in Table 1. Data on the prevalence of hypogonadism in this CCS cohort have recently been published [15].

\section{Controls}

For each childhood cancer survivor, one age-matched control from the general population was identified through the Swedish Population Register. Exclusion criteria were previous diagnosis of tumour in the CNS, a malignant disease other than basal cell carcinoma, or Klinefelter syndrome (47, XXY). Of the 588 potential controls invited, 139 (24\%) agreed to participate. For these subjects, together with a cohort serving as controls in a parallel study on testicular cancer survivors [14] (389 approached controls, 101 accepted inclusion), the distribution of controls having $0,1,2$ or $\geq 3$ children 
Fig. 1 Distribution of medications (growth hormone replacement therapy, testosterone replacement therapy, glucocorticoid replacement therapy, immunosuppressive oral glucocorticoids and calcium + vitamin D) and untreated hypogonadism (S-testosterone $<$ $10 \mathrm{nmol} / \mathrm{L}$ and/or S-LH $>10 \mathrm{IU} /$ L) among childhood cancer survivors

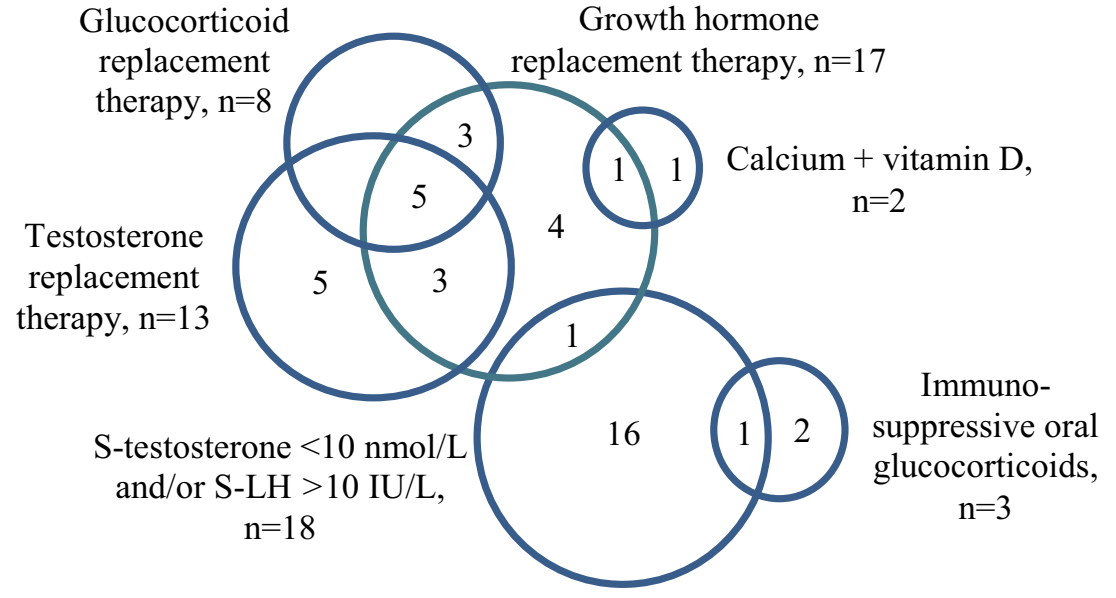

was $12 \%, 42 \%, 35 \%$ and $11 \%$, and $21 \%, 46 \%, 23 \%$ and $10 \%$ among non-participants.

After questioning regarding previous treatment with chemotherapy, radiotherapy and hormonal replacement, eleven controls were excluded due to exclusion of corresponding cancer survivor, and one each due to current malignancy, Klinefelter syndrome or lack of sample material, leaving a final number of 125 . One of the included controls had previously received oral treatment with methotrexate due to psoriasis arthritis. None of the controls received TRT. Background characteristics are presented in Table 1.

The controls were $182.0 \mathrm{~cm}$ in height, and the CCS were essentially similar 180.0. Based on the recorded population mean height of similarly aged Swedish men in 2010-2011 (30-39 years; $180.5(95 \% \mathrm{CI} \pm 0.5))$, all study participants had normal stature [16].

All participants signed an informed consent form, and the Regional Ethics Committee, Lund University, approved the study.

\section{Clinical and laboratory investigations}

Data were collected between December 2009 and August 2013. Participants completed a questionnaire on health status, medication and smoking habits together with a research investigator. Data on fractures were not collected. A stadiometer was used for height measurements to the nearest $0.1 \mathrm{~cm}$, and an electric scale for weight to the nearest $0.1 \mathrm{~kg}$. Body mass index (BMI) was expressed in $\mathrm{kg} / \mathrm{m}^{2}$.

Fasting venous blood samples were drawn between 8:00 and 10:00 a.m. for assessment of serum testosterone and luteinizing hormone (LH) (details described in the Online Resource).

\section{Bone mineral density}

Bone mineral density was assessed at inclusion in this arm of the study when the patients were at a median age of 33.7 years (interquartile range $30.2-40.1)$. BMD $\left(\mathrm{g} / \mathrm{cm}^{2}\right)$ was measured at the femoral neck, total hip and lumbar spine L1-L4 using dual-energy X-ray absorptiometry (DXA) (Lunar Prodigy; GE Healthcare Lunar, Madison, WI, USA), software versions 2.15-7.70 for the majority of participants (see Online Resource for details). DXA measurements were performed by the same research technicians throughout the study period. Stability and accuracy were monitored using a manufacturersupplied phantom three times per week. The precision coefficients (CV\%) for DXA have been reported previously: $0.9 \%$ for the femoral neck, $0.5 \%$ for the total hip and $0.7 \%$ for the lumbar spine L1-L4 [17].

For this study, the Z-score was employed because of the relatively young age of the subjects. Z-scores, a comparison of an individual's bone density with that of a healthy reference population (NHANES III) of the same age, sex and ethnicity and expressed as standard deviations, were obtained from the machine. In this study, we defined low BMD as Z-score below -1.0 . The rationale is based primarily on meta-analysis of 12 cohort studies demonstrating significantly increased risk of osteoporotic fractures for men at Z-scores $\leq-1 \mathrm{SD}$ [3] and in addition because it has also been shown that the majority of fragility fractures occur in patients with BMD in the osteopenic range, i.e. T-score between -1 and -2.5 . [18]. Based on this information, Z-score below -1 can be assumed to imply an increased fracture risk.

\section{Definition of hypogonadism}

Hypogonadism was defined as S-testosterone $<10 \mathrm{nmol} / \mathrm{L}$ and/or S-LH > 10 IU/L, or ongoing TRT [19].

\section{Statistical analysis}

Categorical variables are expressed as numbers and percentages, and continuous variables as means with standard deviations (SDs) or medians (interquartile ranges) in case of non- 
normal distribution. The median (interquartile range) for Stestosterone and S-LH was calculated for the entire CCS group, for subgroups of CCS defined by gonadal status and for controls (Table 1). Applying linear regression models, the following analyses of total hip and lumbar spine BMD were performed, with adjustment for age, BMI and current smoking: (a) all CCS vs. controls; (b) untreated hypogonadal
CCS and CCS receiving TRT, respectively, vs. eugonadal CCS; (c) therapeutic subgroups of CCS (see Online Resource) vs. controls; (d) CCS receiving chemotherapy excluding radiotherapy, and treated with alkylating agents, CCS receiving chemotherapy, excluding radiotherapy, and treated with methotrexate, and CCS receiving chemotherapy, excluding radiotherapy, and also treated with glucocorticoids,

Table 1 Descriptives of childhood cancer survivors (CCS), all and divided into subgroups of CCS based on gonadal status*, and age-matched controls

\begin{tabular}{|c|c|c|c|c|c|}
\hline & CCS, $n=125$ & Eugonadal, $n=93$ & $\begin{array}{l}\text { Hypogonadal untreated }{ }^{\dagger}, \\
n=18\end{array}$ & TRT, $n=13$ & Controls, $n=125$ \\
\hline Age at diagnosis (years) & $9.6(5.4-15.0)$ & $9.6(5.3-16.0)$ & $9.6(5.4-14.4)$ & $8.9(6.5-15)$ & NA \\
\hline Length of follow-up (years) & $24.3(7.1)$ & $24.4(7.4)$ & $24.4(5.8)$ & $23.2(7.7)$ & NA \\
\hline Age at inclusion (years) & $33.7(30.2-40.1)$ & $33.7(29.8-40.0)$ & $32.9(29.6-31.4)$ & $35.7(33.1-39.1)$ & $34.4(30.5-40.6)$ \\
\hline Height (m) & $1.80(1.75-1.86)$ & $1.81(1.77-1.85)$ & $1.81(1.76-1.84)$ & $1.78(1.73-1.88)$ & $1.82(1.78-1.85)$ \\
\hline Weight (kg) & $82.1(72.0-91.5)$ & $80.7(71.1-87.1)$ & $84.3(75.2-102.4)$ & $91.7(77.4-108.4)$ & $81.4(73.3-88.6)$ \\
\hline Body mass index $\left(\mathrm{kg} / \mathrm{m}^{2}\right)$ & $25.1(22.8-27.6)$ & $24.8(22.6-26.8)$ & $26.1(24.5-31.0)$ & $30.3(26.8-31.3)$ & $24.7(22.6-26.9)$ \\
\hline S-testosterone (nmol/L) & $14.1(11.5-17.3)$ & $14.8(13.2-18.1)$ & $9.0(8.0-9.4)$ & $14.4(9.5-17.0)$ & $14.7(11.7-17.6)$ \\
\hline S-LH IU/L $\ddagger$ & $4.0(2.5-5.6)$ & $4.0(2.7-5.7)$ & $4.0(1.9-5.3)$ & N.A. & $3.1(2.2-4.0)$ \\
\hline Smoking, current ${ }^{\#}$ & $10 / 8.2 \%$ & $9 / 10 \%$ & - & $1 / 7.7 \%$ & $17 / 14 \%$ \\
\hline Glucocorticoid replacement & $8 / 6.4 \%$ & $3 / 3.2 \%$ & 0 & $5 / 39 \%$ & - \\
\hline Immunosuppressive glucocorticoids & $3 / 2.4 \%$ & $2 / 2.2 \%$ & $1 / 5.6 \%$ & 0 & - \\
\hline Growth hormone replacement & $17 / 14 \%$ & $8 / 8.6 \%$ & $1 / 5.6 \%$ & $8 / 62 \%$ & - \\
\hline Thyroxine replacement & $17 / 14 \%$ & $9 / 9.7 \%$ & $2 / 11 \%$ & $5 / 39 \%$ & - \\
\hline Calcium + vitamin D treatment & $2 / 1.6 \%$ & $2 / 2.2 \%$ & - & - & - \\
\hline \multicolumn{6}{|l|}{$\operatorname{BMD}\left(\mathrm{g} / \mathrm{cm}^{2}\right)$} \\
\hline Total hip ${ }^{\S}$ & $1.060(0.150)$ & $1.070(0.139)$ & $0.985(0.174)$ & $1.068(0.165)$ & $1.065(0.156)$ \\
\hline Femoral neck ${ }^{\S}$ & $1.038(0.145)$ & $1.049(0.130)$ & $0.961(0.175)$ & $1.051(0.176)$ & $1.034(0.152)$ \\
\hline Spine $\mathrm{L} 1-\mathrm{L} 4^{\alpha}$ & $1.198(0.148)$ & $1.202(0.129)$ & $1.143(0.203)$ & $1.225(0.164)$ & $1.184(0.139)$ \\
\hline \multicolumn{6}{|l|}{ Z-score } \\
\hline Total hip ${ }^{\S}$ & $-0.17(1.06)$ & $-0.05(1.0)$ & $-0.85(1.2)$ & $-0.25(0.92)$ & $-0.13(1.09)$ \\
\hline Femoral neck ${ }^{\S}$ & $-0.14(0.99)$ & $-0.16(0.90)$ & $-0.84(1.2)$ & $-0.18(1.0)$ & $-0.16(1.06)$ \\
\hline Spine $\mathrm{L} 1-\mathrm{L} 4^{\mathrm{a}}$ & $-0.25(1.11)$ & $-0.16(0.98)$ & $-0.84(1.5)$ & $-0.26(1.1)$ & $-0.36(1.10)$ \\
\hline \multicolumn{6}{|l|}{ Low BMD $(Z$-score $<-1)$} \\
\hline Total hip ${ }^{\S}$ & $26 / 21 \%$ & $15 / 16 \%$ & $7 / 39 \%$ & $4 / 31 \%$ & $27 / 22 \%$ \\
\hline Spine L1-L4 & $27 / 22 \%$ & $18 / 20 \%$ & $5 / 28 \%$ & $4 / 31 \%$ & $35 / 28 \%$ \\
\hline
\end{tabular}

*Hormone data missing for $1 \mathrm{CCS}$, which had thyroxine treatment

Hypogonadal untreated S-testosterone $<10 \mathrm{nmol} / \mathrm{L}$ and/or S-LH $>10 \mathrm{IU} / \mathrm{L}$

$\dagger 2$ cases (1.6\% of CCS) presented with isolated elevated S-LH

TRT testosterone replacement therapy

Age at diagnosis, age at inclusion, height, weight, body mass index, S-testosterone and S-LH are reported as medians (interquartile range) due to nonnormal distribution

Length of follow-up is reported as mean (SD)

NA not applicable

$\$ 13 \mathrm{CCS}$ on testosterone replacement therapy excluded

Current smoking, glucocorticoid replacement, immunosuppressive glucocorticoids, growth hormone replacement, thyroxine replacement and calcium + vitamin D treatment are reported as number/\%

\# Smoking data missing for $3 \mathrm{CCS}$ and 3 controls

Bone mineral density (BMD) and Z-score are reported as means (SD)

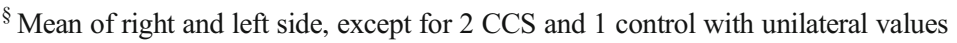

${ }^{\infty}$ Data missing for 1 CCS and 1 control 
separately, vs. controls; and (e) diagnostic subgroups of CCS (see Online Resource) vs. controls.

The subgroups of CCS receiving chemotherapy excluding radiotherapy and receiving alkylating agents, methotrexate or glucocorticoids were overlapping to a large extent; hence, these subgroups were tested separately vs. controls. Cyclophosphamide equivalent dose (CED), a unit developed to quantify the exposure to many different alkylating agents [20], was determined for patients treated with chemotherapy without radiotherapy and receiving alkylating agents.

All analyses were repeated following exclusion of subjects with drugs known to affect BMD and with adjustment for growth hormone replacement, or growth hormone replacement and hypogonadism (see Tables 2, 3 and 4 and Online Resource Tables O1-4 for details). Analyses on untreated hypogonadal CCS and CCS receiving TRT, respectively, vs. eugonadal CCS, were repeated after exclusion of the two hypogonadal CCS with elevated S-LH and normal testosterone levels.

Results are presented as mean difference in BMD $\left(\mathrm{g} / \mathrm{cm}^{2}\right)$ with $95 \%$ confidence interval $(95 \% \mathrm{CI})$.

Using binary logistic regression, comparisons between CCS - total cohort and subgroups as used in analyses of BMD above-were performed by calculating odds ratios (ORs) for low BMD compared with controls or eugonadal CCS, as described above but without adjustment for age, as Z-scores are by definition age-adjusted.

All statistical analyses were performed using SPSS v20 (SPSS Inc., Chicago, IL, USA). $p$ values $<0.05$ were considered statistically significant.

\section{Results}

Sixteen CCS (13\%) presented with low S-testosterone levels and two $(1.6 \%)$ were categorized as hypogonadal due to isolated elevated S-LH. Seventeen controls (14\%) exhibited low S-testosterone, and none with isolated elevated S-LH or TRT.

\section{Childhood cancer survivors vs. controls}

Bone mineral density did not differ statistically significantly between CCS and controls (total hip mean difference -0.014 $(-0.052 ; 0.023) ; p=0.44$ and lumbar spine mean difference $0.006(-0.030 ; 0.041) ; p=0.76)$. These results were robust for exclusion of cases receiving TRT, growth hormone replacement, immunosuppressive oral glucocorticoids, or calcium and vitamin D treatment.

ORs for low BMD were lower in CCS, although not statistically significant (total hip OR $0.94(0.51 ; 1.7) ; p=0.84$ and lumbar spine OR $0.67 ;(0.37 ; 1.2) ; p=0.19)$. Results were roughly unchanged after exclusion of CCS on treatments affecting BMD as described above (Table 2).

\section{Hypogonadal vs. eugonadal childhood cancer survivors}

Compared with eugonadal CCS, untreated hypogonadal CCS had lower BMD at the total hip (mean difference -0.139 ($0.210 ;-0.067) ; p=<0.001$ ) and lumbar spine (mean difference $-0.102(-0.174 ;-0.030) ; p=0.006)$. CCS with untreated hypogonadism had increased risk of low BMD at the total hip (OR 4.1; 95\% CI 1.3; 14; $p=0.018$ ), but not the lumbar spine (OR 1.5; $(0.46 ; 5.1) ; p=0.48)$ (Table 3, Fig. 2).

Among those CCS receiving TRT, neither BMD (mean difference total hip $-0.063(-0.145 ; 0.019) ; p=0.13$; lumbar spine mean difference $-0.032(-0.115 ; 0.051) ; p=0.44)$ nor the risk of low BMD (total hip OR $3.1 ; 95 \%$ CI $0.77 ; 13 ; p=$ 0.11 ; lumbar spine OR $1.9 ; 95 \%$ CI $0.50 ; 7.7 ; p=0.33$ ) was significantly different from eugonadal CCS. All estimates were robust for exclusion of cases on immunosuppressive oral glucocorticoids or calcium and vitamin D treatment, and adjustment for growth hormone replacement (Table 3).

\section{Therapeutic subgroups}

CCS treated with cranial irradiation presented with significantly lower BMD compared with controls (total hip mean difference $-0.076(-0.133 ;-0.019) ; p=0.009$; lumbar spine mean difference $-0.071(-0.124 ;-0.018) ; p=0.009)$. There was no corresponding increase in OR for low BMD (total hip OR $1.5 ; 95 \%$ CI $0.65 ; 3.7 ; p=0.33$; lumbar spine OR 1.5 ; $95 \%$ CI $0.69 ; 3.5 ; p=0.29)$. These estimates were robust for exclusion of cases on immunosuppressive oral glucocorticoids or calcium and vitamin D, and adjustment for hypogonadism and growth hormone treatment (Table 4).

CCS treated with radiotherapy to targets other than the brain, and/or testes \pm chemotherapy had increased BMD at lumbar spine before, but not after, exclusion of cases on immunosuppressive oral glucocorticoids or calcium and vitamin $\mathrm{D}$ treatment, and adjustment for hypogonadism and growth hormone treatment (mean differences $0.068(0.010 ; 0.125)$; $p=0.02$, and $0.058(-0.002 ; 0.117) ; p=0.06$, respectively). No significantly lower risk for low BMD at the lumbar spine was observed (Table 4).

CCS treated with chemotherapy without radiotherapy did not present any significant difference in BMD compared with controls. However, a reduced risk was seen for low BMD at the lumbar spine, before and after exclusion of cases on immunosuppressive oral glucocorticoids or calcium and vitamin $\mathrm{D}$ and adjustment for hypogonadism and growth hormone treatment (OR $0.17 ; 95 \%$ CI $0.04 ; 0.78 ; p=0.02$, and OR $0.18 ; 95 \%$ CI $0.04 ; 0.80 ; p=0.02$, Table 4 ).

CCS treated with chemotherapy without radiotherapy, and receiving alkylating agents, methotrexate or glucocorticoids, had higher BMD and lower ORs for low BMD compared with controls, but none of results were statistically significant 


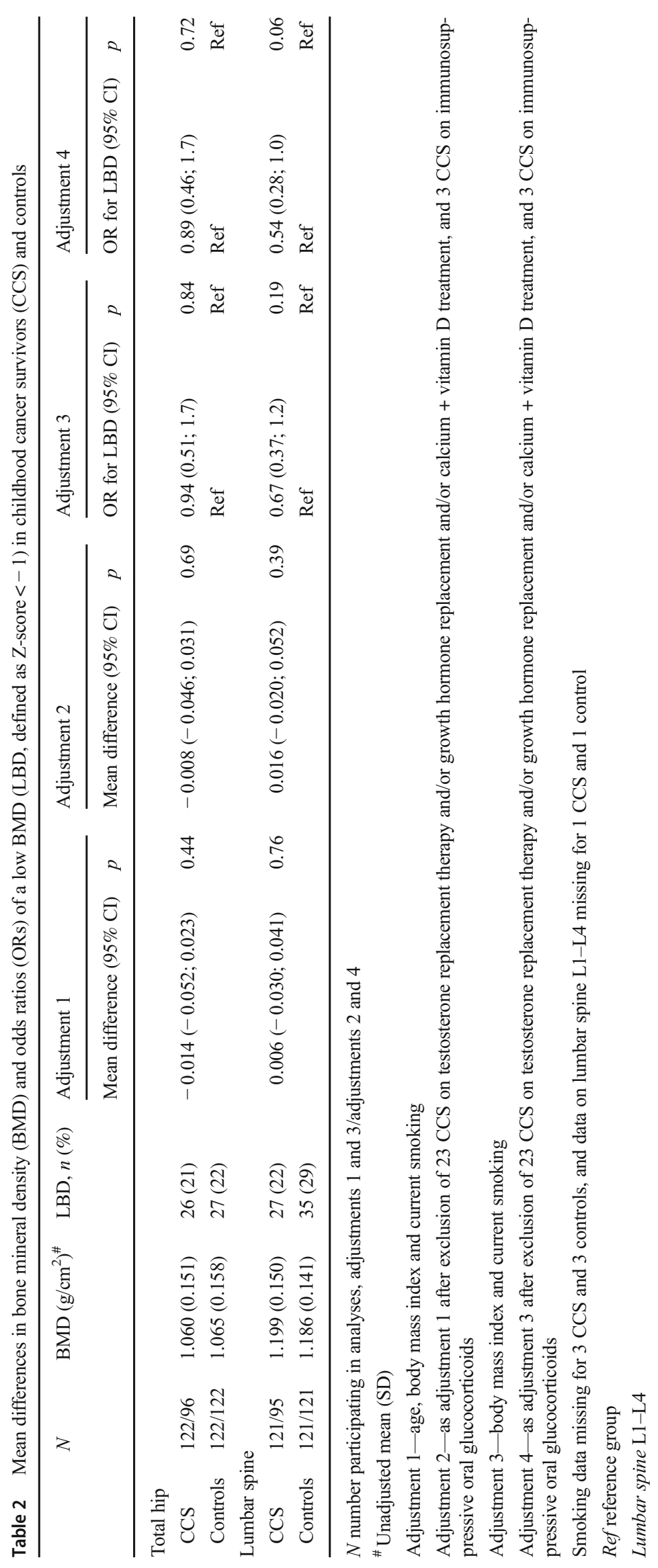




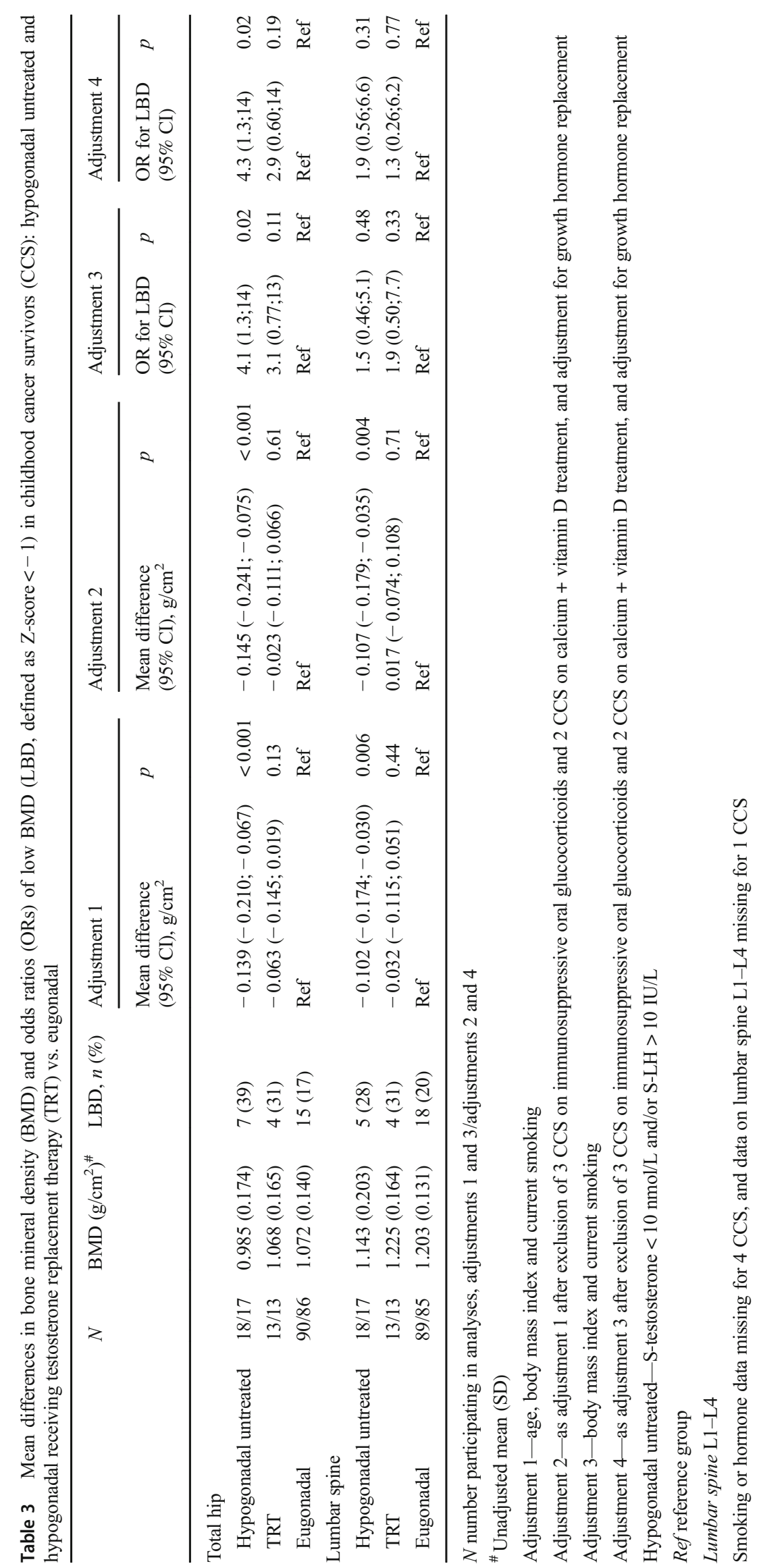




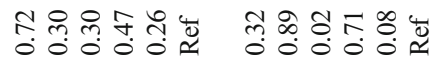

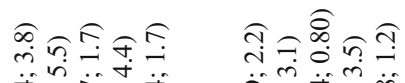

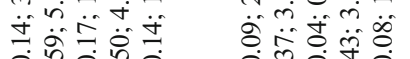

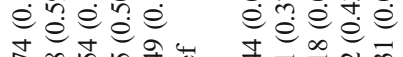

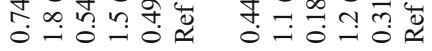

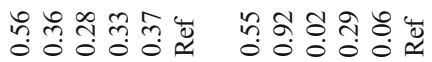

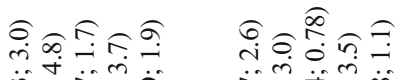

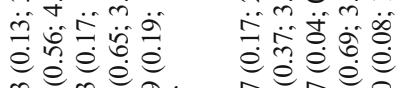

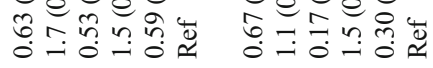

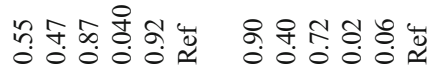

हิ)

잉

ô

$\circ \circ 0.0$

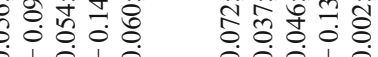

In 1 I I I I n

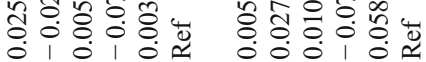

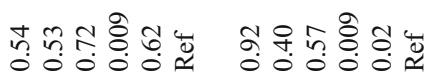

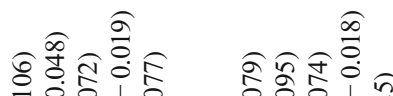

-

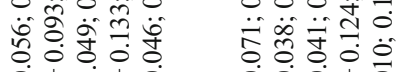

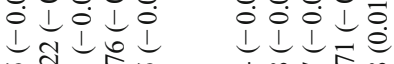

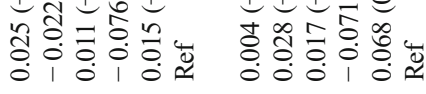

तुण

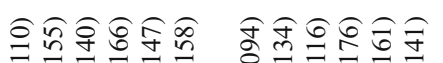

ejejé ejejé

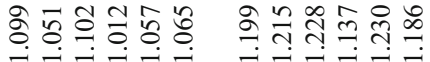

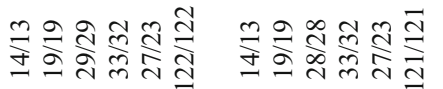

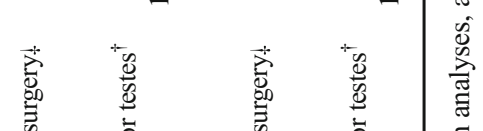

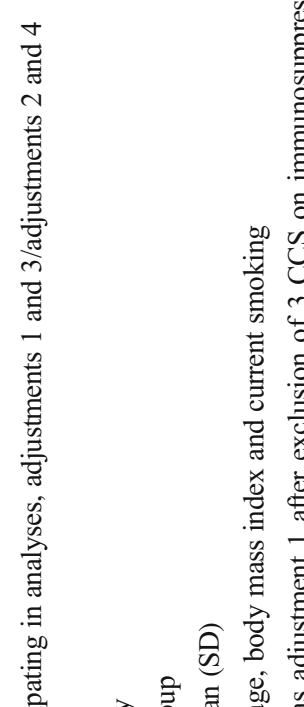

:

㐫

त)

के

옹

है

(n)

昜

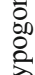

o

क

(2)

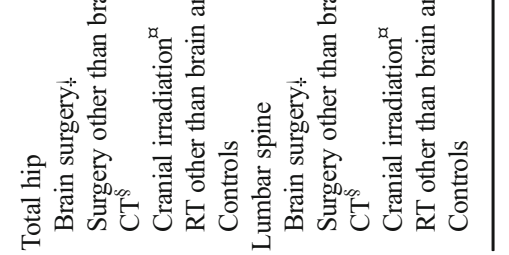

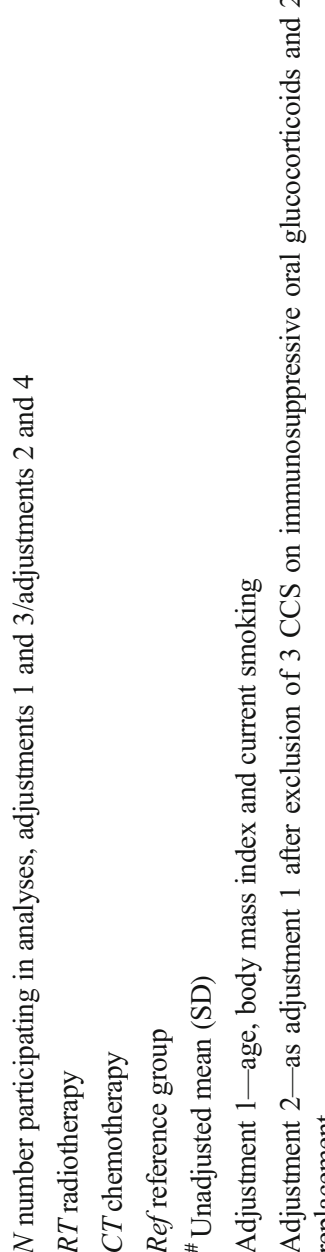

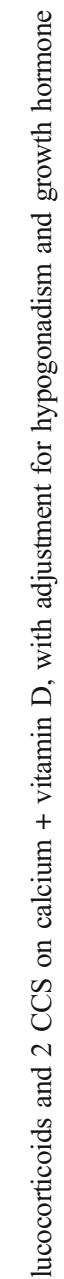

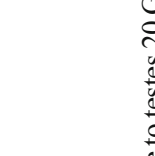

응

(1)

짐

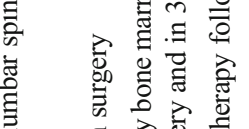

क各忩

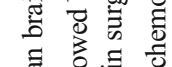

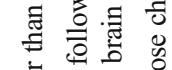

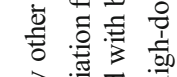

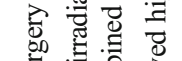

言

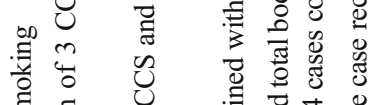

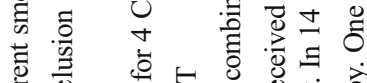

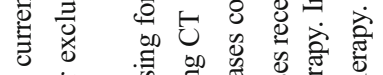

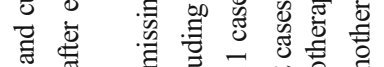

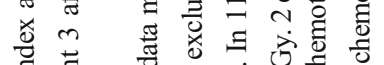

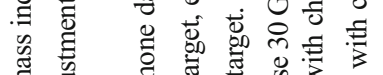

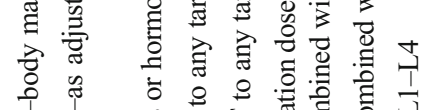

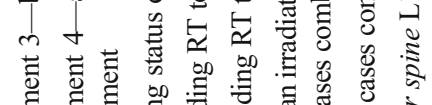

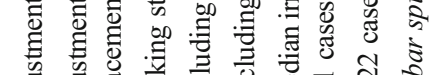

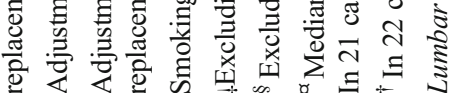


(Online Resource Table O3). Median CED was $4854 \mathrm{mg} / \mathrm{m}^{2}$ and median methotrexate dose was $11 \mathrm{~g} / \mathrm{m}^{2}$.

\section{Diagnostic subgroups}

There was no statistical difference in BMD or risk of low BMD in diagnostic subgroups of CCS compared with controls, with the exception of CCS treated for lymphoma, who had reduced risk of low BMD at the lumbar spine before, but not after, exclusion of cases on immunosuppressive oral glucocorticoids or calcium and vitamin D treatment, and adjustment for hypogonadism and growth hormone treatment $(\mathrm{OR}=0.12 ; 95 \%$ CI $0.02 ; 0.94 ; p=0.04$ and $\mathrm{OR}=0.13$; 95\% CI $0.02 ; 1.0 ; p=0.05$ ) (Online Resource Table O4).

\section{Sensitivity analyses}

For the total cohorts of CCS and controls, mean differences in BMD and ORs of low BMD did not significantly change if one CCS on calcium and vitamin D treatment without growth hormone replacement was kept in the estimations (Online resource Table O1).

When comparing hypogonadal CCS vs. eugonadal CCS, mean differences in BMD and ORs of low BMD were robust for exclusion of the 2 cases with isolated elevated S-LH (Online Resource Table O2).

\section{Discussion}

The most important finding from this study is that BMD among male childhood cancer survivors does not significantly differ from age-matched controls. However, among untreated hypogonadal CCS, BMD was lower both at the hip and lumbar spine compared with eugonadal CCS. This was also expressed as a higher risk of low hip BMD, i.e. hip BMD below the normal range, in this group. Childhood cancer survivors treated with radiotherapy to the brain had lower BMD both at the total hip and lumbar spine compared with controls, this difference being robust for adjustment for hypogonadism.

The fact that no difference was seen for the entire group of CCS compared with controls was probably because not all CCS in our cohort had received extensive cancer treatment (Online Resource, "Childhood cancer survivors, therapeutic subgroups"). Previous studies reporting on reduced BMD in CCS are often based on CCS treated for a specific diagnosis such as acute lymphoblastic leukaemia (ALL) [21-23] or sarcoma [24]. Patients with ALL are extensively treated with chemotherapy, including high-dose methotrexate, in addition to high cumulative doses of corticosteroids. Patients with Ewing's sarcoma and osteosarcoma are treated with intense chemotherapy and surgery, with or without radiotherapy [25].

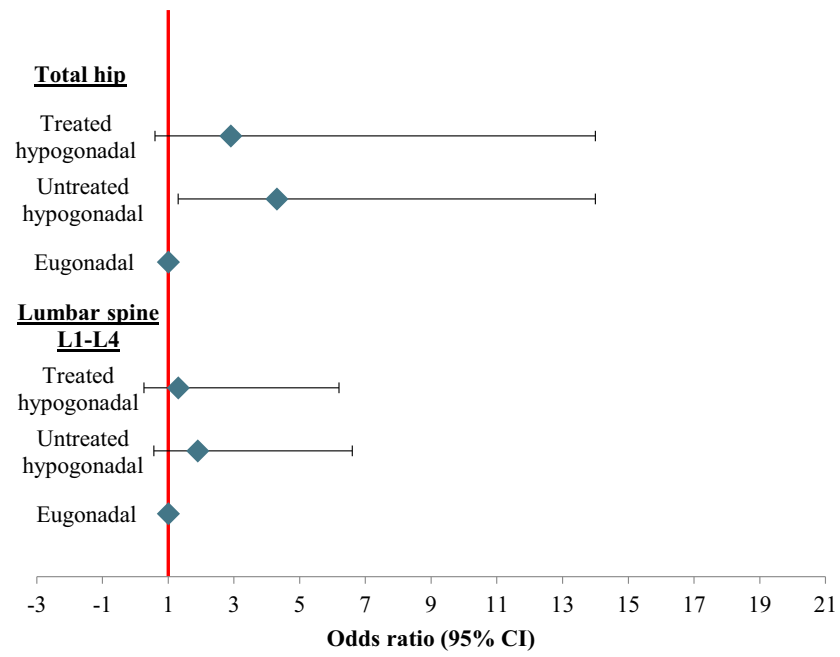

Fig. 2 Odds ratios of low bone mineral density in hypogonadal untreated childhood cancer survivors (CCS) and CCS on testosterone replacement therapy (TRT), after exclusion of 3 CCS on immunosuppressive oral corticosteroids and 2 CCS on calcium + vitamin D treatment, with adjustment for growth hormone replacement. Eugonadal CCS served as the reference group. Untreated hypogonadism was defined as S-testosterone $<10 \mathrm{nmol} / \mathrm{L}$ and/or S-LH $>10 \mathrm{IU} / \mathrm{L}$

In comparison with the St Jude Lifetime Cohort Study (SJLIFE) where $39 \%$ of CCS had total body or lumbar spine BMD Z-score <- 1, [5], the proportion with low lumbar spine BMD was lower in our cohort (22\%). Among SJLIFE patients treated with hypothalamic-pituitary irradiation, $54 \%$ had total body or lumbar spine BMD Z-score $<-1$, compared with $30 \%$ with low lumbar spine BMD in our CCS cohort. However, half of the participants in the SJLIFE were female, and this might, at least in part, explain these differences. In survivors of ALL, the negative impact of cranial irradiation on BMD was reported to be more pronounced in females than in males [26], and men also have a higher increase in BMD following growth hormone replacement than women [27].

Untreated hypogonadism in male CCS was associated with lower BMD at the total hip and lumbar spine, as well as an increased risk of low BMD at the total hip. Testosterone deficiency is a risk factor for low BMD and osteoporosis in elderly men [28], whereas less in known about the association younger men. In a study by Kacker et al., testosterone deficiency was associated with low BMD in men below 50 years with sexual dysfunction or infertility; $38 \%$ having T-scores below -1 at the hip or spine [29]. This is similar to the $39 \%$ prevalence low hip BMD among our hypogonadal untreated CCS.

To the best of our knowledge, only two studies have reported on the association between gonadal function and BMD in adult male CCS. Holmes et al. reported a positive correlation between S-testosterone and BMD in lumbar spine and femoral neck in 29 men with azoospermia treated for Hodgkin disease [9]. S-testosterone was within normal range for most subjects, with mean (SD) $15.2 \pm 1.1 \mathrm{nmol} / \mathrm{L}$, and S-LH was in the upper normal range with mean (SD) $9.7 \pm 0.7 \mathrm{IU} / \mathrm{L}$; hence, many of 
the subjects probably had mild compensated hypogonadism. In a study of male CCS treated for haematological malignancy, Howell et al. [30] reported lower femoral neck BMD in CCS with elevated S-LH and low or low normal S-testosterone, compared with equally treated CCS presenting with normal S-LH and S-testosterone levels. The two latter studies indicate, in line with our findings, that mild hypogonadism can negatively affect BMD in male CCS.

In CCS treated with cranial irradiation, we found lower BMD at the total hip and lumbar spine, which is in line with previous studies $[7,8,26]$. Cranial irradiation in children is a known risk factor for later pituitary malfunctions [31], among others, growth hormone deficiency (GHD) and hypogonadism. Adults with untreated adult-onset GHD have decreased BMD, and adults with childhood-onset GHD have in some, but not all, studies been reported to have lower BMD than controls [32]. Bone mineral density increases after more than 1 year of growth hormone replacement in adults with GHD [27]. The statistically significant associations found in our study were robust for adjustment for hypogonadism and growth hormone replacement. We used the latter as a proxy for GHD as our study was not designed for evaluating growth hormone status, e.g. we did not perform provocative testing for GHD. It is possible that we were unable to adjust for the real impact of GHD on BMD, due to potential undiagnosed and untreated GHD in our cohort. The normal stature of our CCS compared with Swedish men of similar age indicates there is no symptomatic childhood-onset GHD [33]. Therefore, it is unlikely that BMD is underestimated in the CCS - an otherwise potential problem when BMD is measured in children [34]. However, the finding of lower BMD in CCS treated with cranial irradiation indicates that factors other than hypogonadism may play a role in the development of low BMD in male CCS.

Surprisingly, CCS treated with chemotherapy without radiotherapy had decreased risk of low lumbar spine BMD compared with controls. Hypothetically, a healthier lifestyle in cancer survivors could explain this finding, and/or the observed lower risk could be a chance finding.

Alkylating agents have been suggested as a risk factor for low BMD in CCS by causing hypogonadism [7], but are not defined as risk factors for reduced BMD by The North American Children's Oncology Group [6]. For male CCS, cumulative cyclophosphamide dose $>20,000 \mathrm{mg} / \mathrm{m}^{2}$ is a risk factor for testosterone deficiency/insufficiency [6]. Median CED in our cohort of CCS treated with chemotherapy without radiotherapy was well below $20,000 \mathrm{mg} / \mathrm{m}^{2}$, which might explain why we did not find any effect of treatment with alkylating agents on BMD. This is supported by den Hoed et al., finding no increased risk of low BMD at median 17 years after treatment with ifosfamide or cyclophosphamide [35]. Likewise, median methotrexate dose was $11 \mathrm{~g} / \mathrm{m}^{2}$ in our cohort, well below the $>40 \mathrm{~g} / \mathrm{m}^{2}$ associated with decreased BMD [21].

CCS treated for lymphoma had borderline decreased risk of low lumbar spine BMD compared with controls. As concerning haematological malignancies in childhood, children diagnosed with ALL have been reported to have reduced BMD at diagnosis, with a further decrease during therapy $[22$, 23]. Reduced BMD associated with cranial irradiation has been reported in survivors of ALL [36, 37], a median of 8 and 11.5 years after therapy, respectively. However, recovery of BMD in ALL survivors has also been reported, with $67 \%$ of subjects with previous BMD Z-score $\leq-2$ improving at least one standard deviation at a median of 8.5 years later [26]. As our follow-up time was a mean of 24 years, our results can hypothetically reflect such a recovery of BMD, and/or the observed lower risk could be a chance finding.

One of the limitations is the lack of data on duration of TRT and a relatively low statistical power of this part of our calculations. Thus, we cannot conclude if androgen replacement prevents or reverses lowering of BMD in hypogonadal CCS. The effect of TRT on BMD has been debated, and two previous meta-analyses showed only a moderate increase in lumbar BMD but no statistically significant effect on femoral neck BMD after TRT for up to 36 months [38, 39]. However, both meta-analyses included studies on subjects with normal basal testosterone levels, and many studies had only up to 12 months of follow-up. Subsequently, TRT has been found to increase BMD in hypogonadal men at the hip [40] or hip and lumbar spine [41, 42], after treatment for $12[40,41]$ or 36 months [42]. The effect on BMD of TRT for longer than 36 months is not known. Fracture information was not systematically collected in the study, which might have been relevant for assessment of vertebral fractures in particular. However, we do not regard this as a major limitation, since only a single patient had undergone spinal surgery for a vertebral compression and in addition, VFA available for a large portion of the patients identified only one case of vertebral deformity.

An additional limitation is the lack of information regarding lifestyle factors other than smoking, such as physical activity and dietary intake of calcium and vitamin $\mathrm{D}$, factors known to affect BMD [2]. Low participation rate among the controls might also lead to selection bias, with potential overrepresentation of subjects with previous fractures or a family history of osteoporosis. Such a selection bias would, if present, tend to decrease the difference in BMD between controls and patients. Also, the within-patient group comparisons as hypogonadal vs. eugonadal are not dependent on selection of controls. Our data on the number of children among participants and non-participants do not indicate selection of controls due to impairment of reproductive function, but potential selection bias concerning BMD cannot be assessed.

The study has also some obvious strengths. Inclusion of age-matched controls allowed us to draw more valid 
conclusions as considers the bone status of CCS in relation to that in the general population. The size of our patient cohort made it possible to compare eugonadal and hypogonadal men. The diagnosis of hypogonadism was based on hormone values measured in blood samples obtained under standardized and proper conditions - fasting, before $10 \mathrm{am}$. Although only 125 of the original cohort of 427 CCS were included in the current study, the distribution between those having children and childless men was similar in participants and the remaining eligible patients, which indicated a reduced risk of selection bias related to reproductive function.

Due to their novelty, our findings have some important implications in relation to management of male CCS. A significant proportion of CCS are hypogonadal and are, therefore, at increased risk of having secondarily reduced BMD. According to The Endocrine Society's Clinical Guidelines regarding osteoporosis in men, DXA is suggested in hypogonadal men aged 50-69, and testosterone replacement is suggested for men with borderline high risk of fracture and symptomatic testosterone deficiency (S-testosterone < $6.9 \mathrm{nmol} / \mathrm{L}$ ), or S-testosterone $<6.9 \mathrm{nmol} / \mathrm{L}$ and high risk of fracture but contraindications to approved osteoporosis therapy [43]. More than $75 \%$ of our hypogonadal untreated CCS had S-testosterone above this level; hence, our data suggest that BMD is also affected in younger hypogonadal CCS with only moderately lowered S-testosterone.

In conclusion, it is reassuring that BMD was not significantly decreased in the entire group of childhood cancer survivors. However, those presenting with biochemical hypogonadism - representing a significant proportion of this patient group - are at increased risk of impaired bone health. The same was true to some extent for CCS receiving cranial irradiation, and in those men, other factors than low testosterone levels seem to be of significance for the risk of decreased BMD. Taking into consideration the relatively young age of these patients and the age-related decline in testosterone values, DXA should be considered in male cancer survivors with untreated biochemical hypogonadism or previous treatment with cranial irradiation.

Acknowledgements We thank Dr. Thomas Wiebe for the help with collection of clinical and treatment data on the childhood cancer survivors and statistician Anna Åkesson for statistical advice.

Funding information Open access funding provided by Lund University. This study was supported by grants from the Swedish Cancer Society (CAN 2012/661), Swedish Childhood Cancer Society (PROJ12/049), Malmö University Hospital Cancer Fund, Skane University Hospital Fund, Swedish governmental funding for clinical research, and Region Scania Research Fund.

\section{Compliance with ethical standards}

All participants signed an informed consent form, and the Regional Ethics Committee, Lund University, approved the study.
Conflicts of interest Aleksander Giwercman has, more than 2 years ago, been paid for a consulting role by Bayer, and for providing expert testimony on behalf of Ferring Pharmaceuticals. During the last 2 years, Aleksander Giwercman has conducted research projects - not related to current study - funded in part by Ferring Pharmaceuticals. Kristina Åkesson has received lecture or temporary consultancy fees from Amgen, UCB, Eli Lilly, Merck and Sandoz, none related to this study. Ingrid Øra is since 2018 member as consultant in Bayer advisory board.

Open Access This article is licensed under a Creative Commons Attribution-NonCommercial 4.0 International License, which permits any non-commercial use, sharing, adaptation, distribution and reproduction in any medium or format, as long as you give appropriate credit to the original author(s) and the source, provide a link to the Creative Commons licence, and indicate if changes were made. The images or other third party material in this article are included in the article's Creative Commons licence, unless indicated otherwise in a credit line to the material. If material is not included in the article's Creative Commons licence and your intended use is not permitted by statutory regulation or exceeds the permitted use, you will need to obtain permission directly from the copyright holder. To view a copy of this licence, visit http://creativecommons.org/licenses/by-nc/4.0/.

\section{References}

1. Gatta G, Zigon G, Capocaccia R, Coebergh JW, Desandes E, Kaatsch P, Pastore G, Peris-Bonet R, Stiller CA, Group EW (2009) Survival of European children and young adults with cancer diagnosed 1995-2002. Eur J Cancer 45:992-1005

2. NIH Consensus Development Panel on Osteoporosis Prevention, Diagnosis \& Therapy (2001) Osteoporosis prevention, diagnosis, and therapy. Jama 285:785-795

3. Johnell O, Kanis JA, Oden A et al (2005) Predictive value of BMD for hip and other fractures. J Bone Miner Res 20:1185-1194

4. Olszynski WP, Shawn Davison K, Adachi JD, Brown JP, Cummings SR, Hanley DA, Harris SP, Hodsman AB, Kendler D, McClung M, Miller PD, Yuen CK (2004) Osteoporosis in men: epidemiology, diagnosis, prevention, and treatment. Clin Ther 26: $15-28$

5. Hudson MM, Ness KK, Gurney JG, Mulrooney DA, Chemaitilly W, Krull KR, Green DM, Armstrong GT, Nottage KA, Jones KE, Sklar CA, Srivastava DK, Robison LL (2013) Clinical ascertainment of health outcomes among adults treated for childhood cancer. Jama 309:2371-2381

6. Children's Oncology Group (2013) Long-term follow-up guidelines for survivors of childhood, adolescent, and young adult cancers, Version $4.0 \mathrm{http}: / /$ www.survivorshipguidelines.org

7. Kang MJ, Lim JS (2013) Bone mineral density deficits in childhood cancer survivors: pathophysiology, prevalence, screening, and management. Korean J Pediatr 56:60-67

8. Siegel DA, Claridy M, Mertens A, George E, Vangile K, Simoneaux SF, Meacham LR, Wasilewski-Masker K (2017) Risk factors and surveillance for reduced bone mineral density in pediatric cancer survivors. Pediatr Blood Cancer 64(9): p 8

9. Holmes SJ, Whitehouse RW, Clark ST, Crowther DC, Adams JE, Shalet SM (1994) Reduced bone mineral density in men following chemotherapy for Hodgkin's disease. Br J Cancer 70:371-375

10. Chaiban J, Muwakkit S, Arabi A, Jomaa L, Daouk LO, El-Rassi R, Abboud M, El-Hajj Fuleihan G (2009) Modeling pathways for low bone mass in children with malignancies. J Clin Densitom 12:441449

11. Aisenberg J, Hsieh K, Kalaitzoglou G, Whittam E, Heller G, Schneider R, Sklar C (1998) Bone mineral density in young adult 
survivors of childhood cancer. J Pediatr Hematol Oncol 20:241245

12. Polgreen LE, Petryk A, Dietz AC et al (2012) Modifiable risk factors associated with bone deficits in childhood cancer survivors. BMC Pediatr 12:40

13. Romerius P, Stahl O, Moell C, Relander T, Cavallin-Stahl E, Wiebe T, Giwercman YL, Giwercman A (2009) Hypogonadism risk in men treated for childhood cancer. J Clin Endocrinol Metab 94: 4180-4186

14. Isaksson S, Bogefors K, Akesson K, Egund L, Bobjer J, Leijonhufvud I, Giwercman A (2017) Risk of low bone mineral density in testicular germ cell cancer survivors: association with hypogonadism and treatment modality. Andrology 5:898-904

15. Isaksson S, Bogefors K, Stahl O et al (2018) High risk of hypogonadism in young male cancer survivors. Clin Endocrinol 88:432-441

16. Data from Statistics Sweden, available at: http://www.scb.se/hittastatistik/statistik-efter-amne/levnadsforhallanden/ levnadsforhallanden/undersokningarna-av-levnadsforhallandenulf-silc/pong/tabell-och-diagram/halsa/halsa\%2D\%2Dflerindikatorer/. Accessed 24 January 2018

17. Callreus M, McGuigan F, Akesson K (2014) Country-specific young adult dual-energy X-ray absorptiometry reference data are warranted for T-score calculations in women: data from the peak-25 cohort. J Clin Densitom 17:129-135

18. Unnanuntana A, Gladnick BP, Donnelly E, Lane JM (2010) The assessment of fracture risk. J Bone Joint Surg Am 92:743-753

19. Nieschlag E, Behre HM, Bouchard P, Corrales JJ, Jones TH, Stalla GK, Webb SM, Wu FC (2004) Testosterone replacement therapy: current trends and future directions. Hum Reprod Update 10:409419

20. Green DM, Nolan VG, Goodman PJ, Whitton JA, Srivastava D, Leisenring WM, Neglia JP, Sklar CA, Kaste SC, Hudson MM, Diller LR, Stovall M, Donaldson SS, Robison LL (2014) The cyclophosphamide equivalent dose as an approach for quantifying alkylating agent exposure: a report from the childhood cancer survivor study. Pediatr Blood Cancer 61:53-67

21. Mandel K, Atkinson S, Barr RD, Pencharz P (2004) Skeletal morbidity in childhood acute lymphoblastic leukemia. J Clin Oncol 22: 1215-1221

22. Boot AM, van den Heuvel-Eibrink MM, Hahlen K, Krenning EP, de Muinck Keizer-Schrama SM (1999) Bone mineral density in children with acute lymphoblastic leukaemia. Eur J Cancer 35: 1693-1697

23. van der Sluis IM, van den Heuvel-Eibrink MM, Hahlen K, Krenning EP, de Muinck Keizer-Schrama SM (2002) Altered bone mineral density and body composition, and increased fracture risk in childhood acute lymphoblastic leukemia. J Pediatr 141:204-210

24. Holzer G, Krepler P, Koschat MA, Grampp S, Dominkus M, Kotz $\mathrm{R}$ (2003) Bone mineral density in long-term survivors of highly malignant osteosarcoma. J Bone Joint Surg (Br) 85:231-237

25. Marcucci G, Beltrami G, Tamburini A et al (2019) Bone health in childhood cancer: review of the literature and recommendations for the management of bone health in childhood cancer survivors. Ann Oncol 30:908-920

26. Gurney JG, Kaste SC, Liu W, Srivastava DK, Chemaitilly W, Ness KK, Lanctot JQ, Ojha RP, Nottage KA, Wilson CL, Li Z, Robison LL, Hudson MM (2014) Bone mineral density among long-term survivors of childhood acute lymphoblastic leukemia: results from the St. Jude Lifetime Cohort Study. Pediatr Blood Cancer 61:12701276

27. Barake M, Klibanski A, Tritos NA (2014) Effects of recombinant human growth hormone therapy on bone mineral density in adults with growth hormone deficiency: a meta-analysis. J Clin Endocrinol Metab 99:852-860
28. Gaffney CD, Pagano MJ, Kuker AP, Stember DS, Stahl PJ (2015) Osteoporosis and low bone mineral density in men with testosterone deficiency syndrome. Sexual Med Rev 3:298-315

29. Kacker R, Conners W, Zade J, Morgentaler A (2014) Bone mineral density and response to treatment in men younger than 50 years with testosterone deficiency and sexual dysfunction or infertility. J Urol 191:1072-1076

30. Howell SJ, Radford JA, Adams JE, Shalet SM (2000) The impact of mild Leydig cell dysfunction following cytotoxic chemotherapy on bone mineral density (BMD) and body composition. Clin Endocrinol 52:609-616

31. Chemaitilly W, Li Z, Huang S, Ness KK, Clark KL, Green DM, Barnes N, Armstrong GT, Krasin MJ, Srivastava DK, Pui CH, Merchant TE, Kun LE, Gajjar A, Hudson MM, Robison LL, Sklar CA (2015) Anterior hypopituitarism in adult survivors of childhood cancers treated with cranial radiotherapy: a report from the St Jude lifetime cohort study. J Clin Oncol 33:492-500

32. Tritos NA (2017) Focus on growth hormone deficiency and bone in adults. Best Pract Res Clin Endocrinol Metab 31:49-57

33. Chemaitilly W, Sklar C (2009) Disturbances of Growth and Pubertal Development in Childhood Cancer Survivors. In: Yeung S-C, Escalante C P, Gagel R F Medical care of cancer patients, 1st edn. B C Decker inc, Shelton, Connecticut, p 671

34. Binkovitz LA, Henwood MJ (2007) Pediatric DXA: technique and interpretation. Pediatr Radiol 37:21-31

35. den Hoed MA, Klap BC, te Winkel ML et al (2015) Bone mineral density after childhood cancer in 346 long-term adult survivors of childhood cancer. Osteoporos Int 26:521-529

36. Arikoski P, Komulainen J, Voutilainen R, Riikonen P, Parviainen M, Tapanainen P, Knip M, Kroger H (1998) Reduced bone mineral density in long-term survivors of childhood acute lymphoblastic leukemia. J Pediatr Hematol Oncol 20:234-240

37. Kaste SC, Jones-Wallace D, Rose SR, Boyett JM, Lustig RH, Rivera GK, Pui CH, Hudson MM (2001) Bone mineral decrements in survivors of childhood acute lymphoblastic leukemia: frequency of occurrence and risk factors for their development. Leukemia 15:728-734

38. Isidori AM, Giannetta E, Greco EA, Gianfrilli D, Bonifacio V, Isidori A, Lenzi A, Fabbri A (2005) Effects of testosterone on body composition, bone metabolism and serum lipid profile in middleaged men: a meta-analysis. Clin Endocrinol 63:280-293

39. Tracz MJ, Sideras K, Bolona ER, Haddad RM, Kennedy CC, Uraga MV, Caples SM, Erwin PJ, Montori VM (2006) Testosterone use in men and its effects on bone health. A systematic review and metaanalysis of randomized placebo-controlled trials. J Clin Endocrinol Metab 91:2011-2016

40. Svartberg J, Agledahl I, Figenschau Y, Sildnes T, Waterloo K, Jorde $\mathrm{R}$ (2008) Testosterone treatment in elderly men with subnormal testosterone levels improves body composition and BMD in the hip. Int J Impot Res 20:378-387

41. Kenny AM, Kleppinger A, Annis K, Rathier M, Browner B, Judge JO, McGee D (2010) Effects of transdermal testosterone on bone and muscle in older men with low bioavailable testosterone levels, low bone mass, and physical frailty. J Am Geriatr Soc 58:1134-1143

42. Aversa A, Bruzziches R, Francomano D, Greco EA, Fornari R, Di Luigi L, Lenzi A, Migliaccio S (2012) Effects of long-acting testosterone undecanoate on bone mineral density in middle-aged men with late-onset hypogonadism and metabolic syndrome: results from a 36 months controlled study. Aging Male 15:96-102

43. Watts NB, Adler RA, Bilezikian JP, Drake MT, Eastell R, Orwoll ES, Finkelstein JS, Endocrine S (2012) Osteoporosis in men: an Endocrine Society clinical practice guideline. J Clin Endocrinol Metab 97:1802-1822

Publisher's note Springer Nature remains neutral with regard to jurisdictional claims in published maps and institutional affiliations. 